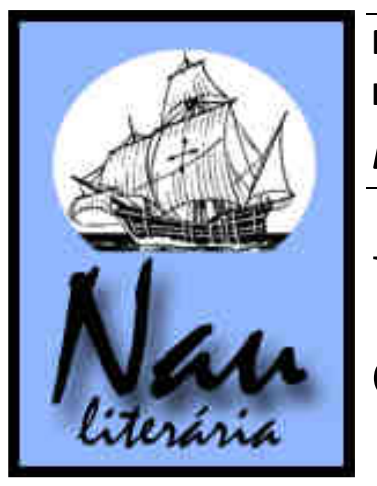

\title{
Uma visão sobre o processo criativo do ator - o literário no teatral
}

\author{
Bia Isabel Noy*
}

Resumo: O presente trabalho é uma reflexão acerca do processo criativo do ator seguido de uma conversa com alguns dos textos estudados durante a disciplina "Teorias do Processo Criativo" ministrada em 2011 pela professora Márcia Ivana de Lima e Silva. O processo criativo de construção cênica abordado foi desenvolvido pela autora durante a realização do seu mestrado na Université Paris VIII. Em seguida, dissolvendo as fronteiras entre o meio literário e o teatral, estabelece-se uma conexão entre os trabalhos do ator/autor. No limiar entre a literatura e o teatro, os processos de criação escrita rompem sua área de atuação para irradiarem suas ideias no meio teatral.

Palavras-chave: processo criativo; criação cênica; literatura comparada.
Resumée: Le travail ici présenté est une réflexion autour du processus créatif de l'acteur suivi d'une conversation avec quelques textes étudiés pendant la discipline «Théories du Processus Créatif » donnée en 2011 par le prof. Márcia Ivana de Lima e Silva. Le processus créatif de construction scénique abordé a été développé par l'auteur durant son master réalisé à l'Université Paris VIII. Par la suite, fondant les frontières entre le domaine littéraire et le théâtral, s'établit une connexion entre les travaux de l'auteur/acteur. Dans le liminaire entre la littérature et le théâtre, les processus de création écrite rompent leurs espaces pour irradier ses idées dans le milieu théâtral.

Mots-clé: processus créatif; création scénique, littérature comparée.

\section{Um começo}

Dentro da abrangência e espaço múltiplo de estudo proporcionado pela literatura comparada, é possível deslocar as ideias instauradas em áreas antes ditas "fechadas" movendo-as por outros caminhos com o objetivo de explorar, expandir e irradiar os conhecimentos produzidos. Tendo em vista este caráter plural da disciplina, nesta reflexão traremos para a cena alguns pensamentos gerados originalmente para fins literários. $\mathrm{O}$ foco principal do pensamento que se seguirá abrange o processo criativo, seja ele locado na literatura ou nas artes cênicas.

As linhas aqui discorridas encontram-se amparada nos textos estudados durante a disciplina "Teorias do processo criativo", no ano de 2011, ministrada pela prof. Márcia Ivana de Lima e Silva. As aulas, bem como os autores trabalhados, incitaram um estreitamento entre a criação no palco e nas páginas. Assim, aqui se tem o objetivo de iniciar uma aproximação entre algumas ideias extraídas da teoria literária e da teatral. Esta abordagem cedeu lugar a

\footnotetext{
Doutoranda em Literatura Comparada pela UFRGS, com sanduíche na Université Paris III - Sorbonne Nouvelle (2013 / 2014). Mestre em Artes Cênicas pela Université Paris VIII - França (2008) e possui especialização em Artes Cênicas pela mesma instituição (2006). Bacharel de Interpretação Teatral em Artes Cênicas pela UFSM (2003).
} 
uma reflexão muito mais profunda e rica que está sendo desenvolvida na pesquisa de doutorado em andamento nomeada "Joana, Femme e Anne Desbaresdes - plenitude e nomadismo em cena".

Cada processo de criação é único e vivenciado de maneira orgânica por quem o experimenta, seja no âmbito teatral, como será aqui exposto, seja no âmbito literário. O corpo do ator figura as mãos do escritor durante a concretização das ideias nas páginas até então em branco. Toda a criação passa pelo corpo, nele se consolidando. A conversa entre os processos criativos das áreas literárias e teatrais se mostra fértil quando ultrapassa as fronteiras fixas e desloca conceitos e ideias para um limiar que permite o entrecruzamento, gerando diferentes maneiras de ver e de perceber os lugares comuns.

Para começar os pensamentos aqui idealizados, é necessário, primeiramente, abordar a formação teatral seguida. Para tanto, peço licença para o uso da primeira pessoa do singular como sujeito da ação. As considerações abordadas são o fruto de um processo de aprendizagem e de criação pessoal e por isso o uso do "eu" faz-se quase que obrigatório.

Sou formada pela Universidade Federal de Santa Maria, em Artes Cênicas. O curso, nesta universidade, tinha até 2010 somente a opção "bacharelado". A partir do ano seguinte a universidade conta com a possibilidade de "licenciatura". Por ser um curso formador de atores e diretores, a prática teatral sempre foi muito valorizada. Desde o primeiro semestre já se interpretavam e se dirigiam cenas. As disciplinas eram as mesmas para quem desejava seguir com a opção "interpretação" ou "direção teatral". Somente no último ano de formação era feita a escolha e então dedicava-se exclusivamente para tal. Sendo assim, minha trajetória parte do princípio de que um ator deve ser capaz de dirigir uma cena, do mesmo modo que um diretor deve ser capaz de atuar. Experimentando ambos os lados, a formação torna-se mais rica e completa: o ator conhece os mecanismos do diretor e o diretor sabe como funciona o processo de criação do ator. Esta dupla formação só vem a valorizar e engrandecer o futuro artista, pois ele se torna um indivíduo com mais vivência, além de o incitar a pensar no espetáculo como um todo. O ator faz parte da criação, e como o diretor ele deve ter pensamento crítico, afinal é ele quem mais se expõe. $\mathrm{O}$ ator de hoje pensa, realiza, opina, faz.

Durante os cinco anos em que passei na universidade, estudamos diferentes linguagens teatrais, como o clow, o bufão, a commedia dell'arte, a máscara, o mimo corpóreo, a tragédia grega, entre outros; além de realizar quase que diariamente um pesado treinamento físico. Este treinamento físico é uma das grandes molas propulsoras para o processo criativo do ator. Visto que o seu instrumento de trabalho é o corpo e é por ele que se manifestam suas intenções, o mesmo deve ser instrumentalizado, trabalhado e construído para que esteja 
disponível para a criação cênica. O corpo deve estar pronto para agir em qualquer momento, seus reflexos devem ser aflorados, e assim como a mente se mantém concentrada, o corpo também deve estar atento aos mínimos detalhes do que o cerca. $\mathrm{O}$ corpo e o pensamento do ator se consolidam em um só organismo para uma atuação inteira e sincera em cena.

Somado ao treinamento corporal, técnica teatral é igualmente fundamental para o processo de criação, abrindo caminhos para o novo na cena. Ela é uma ferramenta da qual o ator deve se servir e se livrar. Isto que dizer que a técnica serve para instigar, sustentar e melhorar a atuação, porém ela não deve ser percebida pela plateia. O papel da técnica no trabalho do ator é o mesmo do tradutor exercendo seu ofício. Segundo Jean-René Ladmiral e Henir Meschonnic, o tradutor deve "être et savoir disparaître" (1981, p. 17). Ele não pode ser o protagonista, ofuscando assim o verdadeiro autor. O tradutor, como a técnica teatral, devem se fazer presentes como um instrumento que nos conduz além. Como um utensílio de importância primordial, ambos são necessários e devem ser explorados, entretanto, precisam passar desapercebidos.

Mesmo sendo um campo de pesquisa de exploração recente, em comparação a outras áreas, o trabalho de criação do ator é alvo de várias e divergentes pesquisas. O curso de Artes Cênicas em Santa Maria segue a linha amparada nas investigações do mestre russo Constantin Stanislavski. Esta mesma linha posteriormente serviu de base impulsora para o pesquisador polonês Jerzy Grotowski (2012).

Constantin Stanislavski (1863-1938) foi um ator e diretor que se sobressaiu como pesquisador teatral. Toda sua trajetória teatral foi baseada na busca por um ator autônomo e criativo. Insatisfeito com o teatro de seu tempo, linguagem, maneira de atuar e postura ética, o pedagogo desenvolve uma pesquisa cênica que culmina em seu "sistema" que compreende o método das ações físicas bem como uma análise do texto teatral a partir das ações realizadas pelos personagens, a análise ativa.

Os estudos de Stanislavski são divididos em duas fases. Por este fato, e pela dificuldade de achar boas traduções de suas investigações, muitos mal entendidos acercam seu nome. De maneira sucinta, a primeira fase do pesquisador é caracterizada pela memória emotiva, na qual o pedagogo afirma que, para interpretar com emoção, o ator deve lembrar-se de fatos emotivos que ocorreram em sua vida pessoal e usá-los como estímulo para a criação cênica. Entretanto, ao decorrer do tempo, Stanislavski percebeu que o corpo do ator não é capaz de memorizar tais emoções. Ou seja, seu método funcionava algumas vezes, mas não era contínuo, o ator não conseguia repetir de maneira constante o estado emocional desejado. Assim, Stanislavski compreendeu que as emoções não devem ser o impulso que gera uma 
ação corporal, e sim o contrário. São das ações realizadas que as emoções despertarão, e desta maneira inicia-se a segunda e mais importante fase do pesquisador.

Para Stanislavski o personagem é consequência das ações do ator como se ele estivesse nas circunstâncias ficcionais da obra. O pedagogo cria o que ele chama de leis orgânicas do comportamento humano na cena teatral. As ações executadas pelos atores seguem o "método das ações físicas", sistematizado pelo encenador no seu trabalho incansável com a pedagogia do ator. A ação física se constitui como "um processo psicofísico de luta contra as circunstâncias dadas para alcançar determinado objetivo, que se dá no tempo

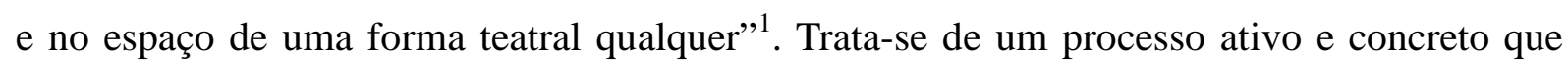
impulsiona o ator a agir. Nele estão envolvidas todas as leis da ação física que Dagostini (2007) chama, em sua tese, de "elementos do sistema": imaginação, concentração e atenção, liberdade muscular, relação, adaptação, tempo- ritmo, circunstância e o "se mágico". Trata-se de entender a natureza humana do ator e suas faculdades necessárias à criação orgânica.

É com base nas experimentações realizadas nesta segunda etapa da pesquisa de Stanislavski que o curso de Artes Cênicas na Universidade de Santa Maria foi fundado. Além de conservar este caráter "stanislavskiano", o curso é conhecido por suas montagens experimentais.

\section{Um caminho}

Independentemente do tipo de montagem teatral que se realizará, ela será sempre muito particular. Aqui, como exemplo, discorreremos sobre a pesquisa de mestrado realizada na Université Paris 8 - Vincennes - Saint-Denis, em Paris (2008), que culminou em duas cenas teatrais baseadas no romance "Perto do Coração Selvagem" de Clarice Lispector.

O objetivo do trabalho era, ao transpor o universo poético da personagem Joana, estudar a influência das línguas - o francês e o português - na cena teatral. Os questionamentos quanto ao influxo dos idiomas apareceram após os ensaios de peças em francês: tinha-se a impressão de que ao falar em francês, o corpo não correspondia ao idioma, somente a voz, como se o idioma ainda não estivesse realmente incorporado.

Desta forma, com o intuito de estudar os idiomas no corpo do ator, a pesquisa foi pensada em etapas para sua melhor organização. Primeiramente criou-se uma cena teatral

\footnotetext{
1 Este conceito não é encontrado na obra de Stanislavski, mas é parte valiosa de seus ensinamentos, sendo disseminado por seus discípulos. Ele foi transmitido pela doutora Nair Dagostini, em aulas ministradas ao departamento de Artes Cênicas da UFSM. A doutora, no período de 1978 a 1981, realizou estudos de PósGraduação no Instituto Estatal de Teatro, Música e Cinema de Leningrado, hoje São Petersburgo, na antiga URSS. Discípula de Stanislavski em terceira geração, foi aluna de A. Kátzman e G. Tovstonógov.
} 
muda - que serviria de base para mais tarde, a implementação dos idiomas. Edificou-se então uma cena na qual o mesmo texto, em francês e em português foi inserido. Assim, já tendo as ações físicas pré-definidas, pode-se, de maneira mais eficaz, investigar as interferências que o ritmo do texto e o ritmo da língua geraram nas ações.

A intenção da pesquisa não era a de contar a história da personagem, porém utilizar-se do universo criado pela autora e do texto por ela escrito como mola propulsora para a criação teatral, bem como ferramenta para uma pesquisa técnica.

O início da investigação foi impulsionado por um treinamento físico, de caráter puramente técnico, para relembrar o corpo a "se organizar". Digo aqui relembrar pois no ano anterior ao da pesquisa de mestrado (2007), em Paris, fui aluna do Conservatório Municipal de Teatro Jean-Philippe Rameau, cujo o foco principal das aulas era o texto falado, havendo então um certo descaso com o trabalho corporal. Por isto, senti a necessidade de "acordar" o corpo, realizando um treinamento físico mais árduo. Para que ele retomasse sua agilidade, reflexo, resistência e elasticidade que havia anteriormente, os ensaios começavam com uma sequencia de acrobacias e exercícios teatrais assimilados ao longo da minha trajetória. Nesta parte, as atividades ainda não eram dirigidas especificamente a um fim voltado à criação desejada.

Quando o corpo começou a mostrar indícios de que estava pronto e disponível para o trabalho, comecei a pensar sobre a metodologia a ser usada para a criação da cena. Para conservar o caráter de brincadeira e jogo que encontramos no início do texto de "Perto do Coração Selvagem”, optei por utilizar basicamente o jogo e a improvisação como método de criação. Nas práticas teatrais entende-se jogo e improvisação como dois conceitos que estão implicados um no outro. Não há improvisação sem jogo, tampouco jogo sem improvisação. Neste trabalho decido então de tratá-los como sinônimos.

Existem dois tipos de jogos, o jogo com regras e o jogo livre ${ }^{2}$. A primeira forma possui um objetivo claro, pressupõe um "lugar onde se pretende chegar" e, para tanto, usam-se estímulos que direcionam os atores para a cena que está prevista. Logo, estabelecem-se regras. A segunda forma, como o próprio nome já diz, não possui regras e nenhum recorte. Não se sabe ao certo aonde se chegará. O jogo livre é o acaso, abrem-se caminhos para o campo do possível e o ator, evolvido em todas suas faculdades imaginativas, coloca-se em estado de criação.

2 O sociólogo francês Jean Duvignaud (1997) foi quem cunhou o conceito de jogo livre. Para ele, jogo livre são todas as manifestações humanamente organizadas que não possuem explicação nem finalidade. São inúteis se forem analisadas dentro dos padrões da vida racional cotidiana. Assim, o jogo livre não possui regras, sua natureza é lúdica e imagética. 
Durante a composição das cenas, foi usado tanto o jogo livre quanto o jogo com regras. Como estímulo para a improvisação, objetos simples do cotidiano foram selecionados. Um balde, duas garrafas de vidro, uma toalha de mesa e dois pompons de cortina. A escolha por estes objetos ocorreu de maneira natural e mesmo ocasional, pois os encontrei no lugar de ensaio e acabei por utilizá-los na cena: jogo com o acaso.

Ao se trabalhar com os objetos, eles eram desprovidos de suas funções normais e ganhavam outro significado - eles foram profanados. Como nos propõe Agamben (2007), a profanação cumpria seu papel retirando da esfera do sagrado as reais funções dos objetos, abrindo caminhos para que eles sejam encarados sob outro ângulo. As garrafas se tronaram flautas, o balde serviu desde piscina até banco e os pompons obviamente não prendiam mais a esplendorosa cortina do palco. Durante esta brincadeira concentrada, sequencias de ações forma se estabelecendo. Elas não tinham, ainda, nenhuma relação com o texto.

Para penetrar mais na atmosfera do texto de Lispector, imagens do romance, bem como passagens escolhidas serviram de mote para a improvisação. Como exemplo de imagem trabalhada, tem-se: “[...] e ela respirava como um doente que tivesse passado pelo grande perigo. Alguma coisa ainda balbuciava dentro dela, porém seu cansaço era grande, tranquilizava seu rosto em máscara lisa e olhos vazios" (1998, p. 199), ou ainda "a paz que vinha dos olhos do boi, a paz que vinha do corpo deitado do mar, do ventre profundo do mar, do gato endurecido sobre a calçada..." (1998, p. 30).

Igualmente foram extraídos do texto alguns verbos de ação que estimularam a criação de cenas. Os verbos em questão apareceram no momento em que uma rápida análise do texto foi efetuada. Este estudo do texto teve como base os princípios desenvolvidos por Stanislavski para seu método de análise ativa. Para tanto, uma leitura dinâmica e atenta foi requisitada. Como resultado, descobriu-se verbos de ação da personagem fundamentais para o desenrolar da trama. Os verbos, pelo seu caráter ativo estimulam o ator a agir fisicamente, evitando que movimentos vazios e sem sentido sejam confundidos com ações reais providas de verdadeiras intenções. Como exemplo pode-se citar: brincar/jogar, esperar, beijar, descer as escadas, esconder-se, brigar, viajar. A partir destes verbos criaram-se situações que após serem trabalhadas e lapidadas ultrapassaram o simples significado que as originou, ganhando mais profundidade e interesse cênico.

Ainda, lendo fragmentos do texto, me vinham imagens, posturas corporais e vozes que inspiravam o jogo e a construção de um movimento ou de uma ação. A partir deste material, e da sequência criada com os objetos, iniciou-se o trabalho de construção de um esqueleto cênico. 
Com a concentração necessária, aberta para o jogo e para o acaso, comecei a experimentar diferentes maneiras de juntar os pedaços que haviam sido criados, fossem eles originados pelo jogo com os objetos ou estimulados pelas imagens, pelos extratos e pelos verbos de ação retirados do romance. Após vários ensaios de experimentações cênicas, elaborou-se a construção de uma cena de aproximadamente 30 minutos. O próximo passo na pesquisa foi a inserção do texto. E a pergunta: qual texto em quais partes?

A escolha dos fragmentos que foram utilizados não obedeceu a nenhum critério em especial. Intuitivamente selecionei fragmentos que me eram prazerosos de ler e que, segundo Barthes, me proporcionaram "la jouissance":

Celui qui met en état de perte, celui qui déconforte (peut-être jusqu'à un certain ennui), fait vaciller les assises historiques, culturelles, psychologiques, du lecteur, la consistance de ses goûts, de ses valeurs et de ses souvenirs, met en crise son rapport au langage. (1982, p. 23)

As várias passagens do texto, sempre a serviço do prazer, foram sendo cortadas, coladas, recortadas e recolocadas estabelecendo-se então uma "nova dramaturgia".

Assim, respondendo a pergunta feita anteriormente, confesso que mais uma vez fui levada pela experimentação e pelo acaso. Após diversas repetições e tentativas, decidi e assumi respeitar a ordem segundo a qual eu havia retirado os fragmentos do romance. Logo, com texto foi inserido, o trabalho sobre o ritmo da cena começou.

Esta parte do trabalho de criação é a que mais me dá prazer, a que mais me estimula e me transporta para lugares outros que o cotidiano. Particularmente, me fascina fazer e refazer e repetir e mudar e transformar o que já está "fechado". Ao contrário do que se possa pensar, é possível sim improvisar no interior de uma estrutura. A improvisação, o caráter do jogo não devem nunca desaparecer das cenas já edificadas. São eles os responsáveis pela vivacidade e frescor que a cena necessita para sua autenticidade e organicidade.

Neste trabalho especificamente, o texto (tanto em francês, quanto em português) foi trabalhado até perder seu significado primeiro, as palavras pronunciadas não carregavam mais em si seu sentido. Elas se tronaram música, gerando um novo ritmo. Durante a pesquisa notei que este processo de jogo com o texto - até que ele perca seu sentido - foi mais fácil com a língua francesa, pois o desprendimento do significado aconteceu de forma mais rápida e eficiente.

Todo este processo de criação cênica e de trabalho com o texto é semelhante com aquele vivenciado durante minha formação na UFSM. O mote para a criação de uma ação cênica pode ser simples: uma folha de jornal, um texto de jornal, um verbo de ação, uma imagem, etc... . A emoção (tristeza, raiva, alegria) nunca é a propulsora da ação cênica; a 
emoção que se carrega para a cena é assim uma consequência de um trabalho árduo de repetição. Como já dizia Stanislavski (1999), o corpo só pode se recordar das ações nele incorporadas, o corpo possui memória e deve-se utilizá-la. A emoção virá no desencadear da ação psicofísica realizada.

\section{Um entrecruzamento}

Durante a disciplina "Teorias do Processo Criativo", visitamos diversos autores e maneiras com as quais eles veem o processo criativo. Durante as aulas pode-se perceber que mesmo em se tratando de literatura, muitos aspectos abordados se assemelham com o teatro (não somente em relação ao texto dramatúrgico, mas em relação com a prática do trabalho do ator).

Começarei a discussão sobre as diferenças e semelhanças do teatro e da literatura com o texto "Teses sobre o Conto" do livro "O Laboratório do Escritor" (1994) de Ricardo Piglia. $\mathrm{O}$ autor analisa a estrutura do conto, gênero este que carrega consigo duas histórias. Para exemplificar esta constatação, Piglia cita os clássicos contos de Poe: em primeiro plano há a história narrada e no fundo tem-se a segunda história, a que se constrói em segredo, que não está explícita e que será (ou não) desvelada somente no final.

No teatro também possuímos um elemento "secreto". Este, assim como no conto, se localiza nas entrelinhas e é chamado de subtexto. Piglia afirma que "a história secreta é a chave da forma do conto e suas variantes" (1994, p. 39). Permito-me aqui adaptar esta frase para o meio teatral, onde diria: "o subtexto (a história secreta) é a chave para uma interpretação orgânica ${ }^{3}$ ".

O subtexto seria o que no conto se constrói ocultamente; as entrelinhas do texto, o que está por trás da palavra e que serve como uma motivação para o ator, além de auxiliá-lo a construir uma linha lógica de ações para o personagem. O subtexto é a "vida del espíritu humano del papel" (KNEBEL, 2004, p. 134). É através dele que o ator enriquece sua interpretação, pois é esmiuçando o texto e compreendendo o "por detrás" que ele será capaz de criar sutilezas tanto na fala quanto nas ações do personagem. O subtexto é um dos importantes fatores que levam a uma atuação orgânica e sincera, pois ele é quem dita a real intenção do personagem.

Diferentemente do conto, onde a história escondida é outra, o subtexto não difere da narrativa principal, ou seja, ele não é outra história. O oculto aqui nos faz perceber a realidade

3 O termo "orgânico" no meio teatral significa uma atuação sincera, completa, onde corpo e mente estão integrados. 
de outra maneira. O secreto desvenda os verdadeiros objetivos dos personagens. No teatro, ler as entrelinhas significa compreender o porquê das ações do personagem, significa complementar e enriquecer a construção cênica do mesmo.

Percebe-se desta forma, que tanto na literatura como no teatro, o texto é feito para ser saboreado, esmiuçado, interpretado. O interpretar aqui se refere à ideia proposta por Barthes, tomada emprestada de Nietzsche: tem-se a ideia de apreciar o texto por suas possibilidades plurais (BARTHES, 1991, p. 211), e não de fechá-lo em uma só significação. Ao buscar os não ditos, as sutilezas do texto, ou a "fenda", a "intermitência" como diz Barthes (1982), o leitor terá uma leitura mais prazerosa, completa e enriquecerá sua imaginação, pois o personagem que antes era visto por um ângulo, será agora exposto como se ele fosse algo a ser examinado, desvelado. Leitor e ator precedem um prazeroso trabalho de "busca" pelo o que a narrativa tem a oferecer. As palavras formam escritas como se elas fossem uma cortina, e nós leitores/atores as lemos como crianças tentando ver o que está escondido, logo ali atrás.

Continuemos a conversa com Umberto Eco e seu texto "Pós-escrito a O Nome da Rosa" (1985). Logo no início do seu relato Eco afirma que "um romance é uma máquina para gerar interpretações" (1985, p. 8) e de início já me surpreendo pensando "o teatro é também uma máquina de gerar interpretações”. Começo assim a leitura do livro com um sorriso nos lábios e com a certeza de que seu depoimento sobre a construção do romance me remeterá as muitas questões abordadas ao se realizar uma montagem cênica.

A expectativa sobre a leitura do texto foi superada e Eco trata diversos problemas de âmbito teatral. Um deles é a verossimilhança da criação. Ele, o autor, assim como o ator, pensa e analisa o universo da obra a ser montada. Deve-se construir um mundo que seja crível, mesmo que este seja fantasioso. Os dois artistas tem a função de nos convencer de que aquele universo realmente existe, por mais absurdo que ele possa parecer. Ator e autor devem edificar elementos concretos para que o público/leitor entre na atmosfera por eles criada.

$\mathrm{O}$ mesmo ocorre em relação às ações dos personagens. Elas devem ser coerentes com o temperamento de cada um deles, e serem, sobretudo, bem construídas. Cada personagem tem um objetivo específico, que talvez o leitor/público não assimile desde o início. Mas ator e autor, para a construção do herói, devem saber o que querem com aquele personagem.

O mote da obra literária e da obra teatral, pelo que mostra Eco é o mesmo: resolver um problema. No caso destas duas artes, o caminho para encontrar as soluções será distinto, porém não menos árduo. Enquanto Eco escreve e reescreve, o ator cria, recria e repete. A busca pela solução do problema é nos dois casos consequência de muito trabalho. Mas "quem cria" o problema? 
Umberto Eco mostra uma inquietação em relação à trajetória dos personagens. $\mathrm{O}$ romance necessita de um conflito, de obstáculos. Desta maneira, o autor cria obstáculos para que seus personagens possam superá-los dando continuidade à história. Os obstáculos são o trampolim para o protagonista.

O ator por sua vez, através da análise da ação do personagem (análise ativa - método elaborado por Stanislavski), identifica estes obstáculos e utiliza-os como mola propulsora para a composição da figura cênica. São os obstáculos que impulsionam as faculdades criativas e imaginativas tanto do escritor como do ator.

Autor, bem como ator e diretor necessitam definir os objetivos e contratempos dos personagens para poder dar-lhes vida. As perguntas que tanto fazemos no teatro, como: "o que o personagem quer com isso?", “porque de tal ação?”, “aonde ele quer chegar?”, são, segundo os escritos de Eco, feitas também pelo autor no processo de criação da obra.

Outro fator importantíssimo do meio cênico abordado pelo escritor é o ritmo do texto, a respiração. Eco diz: "Um grande romance é aquele em que o autor sempre sabe em que momento deve acelerar, frear e de que maneira dosar esses movimentos de pedal no quadro de um ritmo fundo que permanece constante" (1985, p. 37). Pode-se afirmar com toda propriedade que tal constatação é válida tal e qual para o teatro. Um bom ator ou diretor deve saber dominar o ritmo das cenas individuais e do espetáculo como um todo. Nos aprofundaremos na questão do ritmo nas linhas a seguir, com Ítalo Calvino.

Em "Seis propostas para o próximo milênio" (1988) de Ítalo Calvino, identifica-se igualmente princípios cênicos. Ao começar abordando a "leveza", o autor nos remete ao treinamento corporal do ator, ao afirmar "que a leveza está associada à precisão e à determinação, nunca ao que é vago ou aleatório" (1988, p. 28). A precisão na arte de atuar é um elemento fundamental, o corpo do ator tem que ser leve, preciso e limpo. Para atingir estas capacidades o ator disciplinado realiza diariamente um treinamento para que seu corpo responda às exigências cênicas. Somente com o domínio total do corpo, e sabendo controlá-lo e explorar suas capacidades é que o ator estará apto para as mais diversas composições de personagens.

Com um corpo preciso, as ações realizadas em cena também o serão. O público só acreditará no ator se o próprio souber e acreditar no que está fazendo. Por isso não há espaços para titubeios ou hesitações. Em uma atuação orgânica, mente e corpo agem juntos, de maneira coesa e precisa.

Além disto, ao colocar a leveza como subtração do peso, Calvino também toca no ato teatral. No palco, o ator deve ser leve, por mais que a cena que ele realize seja pesada - 
mesmo ao representar uma tragédia, como Medéia, por exemplo, o ator tem que ser capaz de dominar seus movimentos e ser leve. A energia corporal deve ser pesada, não o corpo. É o clima instaurando pelo ator que tornará o espetáculo pesado, não seus passos carregados ou suas ações descontroladas e desmedidas. Cada gesto é controlado e possuidor de um propósito, e por mais pesado que seja, ele é regido pela leveza.

Na segunda proposta, a "rapidez", Calvino faz uma alusão a Poe e o seu tempo de "uma sentada" (válido para o conto). No teatro, esse tempo de "uma sentada" não deve ser observado no tempo de leitura do texto dramatúrgico, mas sim no tempo rítmico do espetáculo como um todo. Como disse Umberto Eco, anteriormente citado, o autor - como diretor teatral - deve ter o sentido aflorado para perceber o tempo da narrativa. Faz-se necessário que os olhos externos sejam sensíveis a ponto de saber quais partes são mais importantes, merecendo uma atenção especial e quais partes podem passar mais rapidamente. O ritmo de um espetáculo ${ }^{4}$ é muito importante, pois ele tem o poder de cativar o espectador. Quantas montagens de Shakespeare já não formam feitas e, apesar da genialidade do texto, não foram bem sucedidas? A culpa, neste caso não poder ser atribuída ao autor. Um bom texto teatral não garante uma encenação interessante e viva. O ritmo da escrita deve ser trabalhado para o palco, com suas oscilações, quebras e continuidades que atribuem as surpresas e o sucesso da montagem. Ainda, não se pode associar o ritmo de um espetáculo ao seu tempo de duração. Há peças com mais de quarto horas, nas quais o tempo entre em suspensão e não se percebe sua passagem. Isto porque os atores, dando conta do texto, sustentam com propriedade a ação cênica. Calvino utiliza uma citação provinda latim muito pertinente para trabalhar a sutileza do ritmo: "apressa-te lentamente" (1988, p. 60). Atores, escritores e diretores devem se apressar para atrair a atenção do público, devem se apressar para narrar a história ou as impressões desejadas, entretanto é esta pressa lenta, uma pressa com intervalos de respiração que permitem o acompanhamento do leitor/espectador.

$\mathrm{O}$ autor, em sua terceira proposta define a exatidão: 1) projeto de obra bem definido; 2) evocação de imagens visuais nítidas; 3) linguagem precisa (1988, p. 71). Creio que a exatidão pode-se unir ao conceito de leveza, no sentido da precisão. A exatidão, como Calvino diz, começa já no processo de criação, no projeto, na evocação. Não é algo que se adquire depois da obra pronta, a exatidão é uma ferramenta para que a obra tenha boas qualidades. Mais uma vez volta-se a falar do papel do treinamento no trabalho do ator: todo ele possui

$4 \mathrm{O}$ ritmo no teatro é trabalhado em diversas esferas. Existem o ritmo do espetáculo como um todo, os ritmos individuais das cenas e há ainda o ritmo do ator e das ações que ele executa. Neste momento, ao falar do ritmo de uma sentada, comparamos somente com o ritmo do espetáculo em geral, sem entrar em detalhes no tempo/ritmo do ator ou da cena. 
suas raízes na exatidão dos movimentos e dos exercícios, culminando em ações leves, precisas e sem hesitações.

Além de ter evocado novamente o treinamento, podemos ainda trabalhar a exatidão durante o processo criativo dirigido a um fim específico. O diretor, ao ter um projeto de montagem bem definido, ao delimitar a linguagem a ser utilizada e ao guiar o ator a construir imagens concretas, construirá amplas possibilidades para a elaboração de um trabalho coerente. O conhecimento do objetivo maior, tanto da obra literária quanto da teatral, é fundamental para sua coesão no ato criativo.

O fator da "visibilidade", quarta proposta de Calvino, mostra dois tipos de processos imaginativos: "o que parte da palavra para chegar à imagem visiva, e o que parte da imagem visiva para chegar à expressão verbal" (1988, p. 99). Podemos dizer que no teatro estes dois processos também existem, dependendo certamente da proposta do diretor. Se o grupo de artistas decide realizar a montagem de acordo com um texto, eles partirão da palavra, ou de sua análise (subtexto) para a criação prática. Porém, se a trupe se propõe a criar uma dramaturgia de acordo com as improvisações livres realizadas nos ensaios, sem nenhum texto pré-determinado, as imagens geradas irão servir de estímulo para a construção do texto dramático.

Ainda nesta proposta, Calvino discorre sobre a capacidade de "pensar por imagens". E é exatamente isto que o ator faz durante o processo criativo, ele pensa em imagens e realiza em ações. As imagens construídas pelo ator são um estímulo para a criação cênica, a imaginação é a fonte criadora do ator, que auxiliada pela técnica, pode ser exprimida por um corpo disponível (corpo este preparado pelo treinamento).

Ao falar sobre "multiplicidade", última proposta, o autor aborda a "rede de conexões" presente no nosso cotidiano. O conhecimento múltiplo está presente em todas as artes. Música, teatro, plásticas, criam um feixe de conexões que ampliam fronteiras e que fazem com que a interdisciplinaridade seja assunto constante em discussões não só literárias como artísticas. Conexões estas que aqui neste apanhado tentou-se estabelecer entre o teatro e a literatura. 


\section{Referências}

AGAMBEN, Giorgio. Profanações. São Paulo: Boitempo Editorial, 2007;

BARTHES, Roland. Le plaisir du texte. Paris: Éditions du Seuil, 1982; L'aventure sémiologique, Édition du Seuil, Paris, 1991;

CALVINO, Ítalo. Seis propostas para o próximo milênio. São Paulo: Companhia das Letras, 1988;

ECO, Umberto. Pós-escrtio a O Nome da Rosa. Rio de Janeiro: Nova Fronteira, 1985;

DAGOSTINI, Nair. O método de análise atica de K. Stanislavski como base para a leitura do texto e da criação do espetáculo pelo diretor e ator. 2007. 259. Tese - Universidade de São Paulo, 2007;

DUVIGNAUD, Jean. El juego Del juego. Santafé de Bogotá: Fondo de Cultura Econômica, 1997;

GROTOWSKI, Jerzy. Vers un théâtre pauvre. Paris: L'Âge d'Homme, 2012;

LADMIRAL, Jean-René e MESCHONNIC, Henri. Poétiques de... /Théorèmes pour... la traduction, Langue Française, n51, pp. 3-18, setembro 1981.

LISPECTOR, Clarice. Perto do Coração Selvagem. Rio de Janeiro: Ed. Rocco, 1998;

PIGLIA, Ricadro. O Laboratório do Escritor. São Paulo: Iluminuras, 1994;

KNÉBEL, María Ósipovna. La Palabra en la Creación Actoral. Madrid: Ed. Fundamentos, 2004;

STANISLAVSKI, Constantin. Ma vie dans l'art. Paris: L'Âge d'Homme, 1999; . La formation de l'acteur. Paris: Éditions Petite Bibliothèque Payot, 1963. 